\title{
Simulation Research of the Concentration Distri- bution of Indoor Inhaled Particulate Matters
}

\author{
$\underline{\text { http://dx.doi.org/10.3991/ijoe.v9iS2.2560 }}$ \\ Hongli Liu ${ }^{1}$, Xiong Zhou ${ }^{1}$ and Huan Sun ${ }^{1}$ \\ ${ }^{1}$ School of Automation, Wuhan University of Technology, Wuhan, China
}

\begin{abstract}
Taking the small offices and residences for a studied object, this paper analyzes the process and major factors to affect the concentration and size distribution of indoor inhaled particulate matters, founds the deposition model, the penetration model and the mass balance model to predict the concentration and sizer distribution of indoor inhaled particulate matter. According to the real-time measuring data, the feature of building defense structure and the concentration and size distribution of outdoor inhaled particulate matters, the deposition ratio, the penetration factor and indoor air capacity are used as the input parameters of the mass balance model. We have put to the proof of the deposition model, the penetration model, simulated the mass balance model, then predicted the concentration and size distribution of indoor inhaled particulate matters.
\end{abstract}

Index Terms-Indoor Inhaled Particulate Matter, Concentration Distribution, Deposition, Penetration, Simulation Research.

\section{INTRODUCTION}

Indoor air pollution can be considered as some substances into room caused by human activities or natural processes, which can damage human health because of its sufficient concentration and sustained enough time ${ }^{[1]}$. According to a survey, people spend more time than $90 \%$ indoors everyday, so Indoor environmental quality is closely related to human health. The diameter of inhaled particulate matters have relevance to its deposition, stranded and removal in respiratory. Generally speaking, it is less possibility that particles with diameter more than $30 \mu \mathrm{m}$ enter respiratory, most of particles with diameters between 10 and $30 \mu \mathrm{m}$ deposit in the nasal cavity, and particles with diameters between 5 and $10 \mu \mathrm{m}$ can enter trachea and bronchus. Only those particles with diameters less than $2.5 \mu \mathrm{m}$ can enter the deeper respiratory tract and scatter on the pulmonary alveolus. Obviously, particles with diameters less than $2.5 \mu \mathrm{m}$ is the most dangerous ${ }^{[2]}$.

Indoor inhaled particulate matter concentration is decided by the ratios of outdoor particles in and out of building, elimination, transition, resuspended and preduction. As the major factors, deposition and penetration present a certain statistics pattern in broad particle size range. Specially, outdoor inhaled particulate matter concentration is very important effect on Indoor inhaled particulate matter concentration, so it is necessary to studying their relations.

\section{THE MASS BALANCE MODEL}

Assumed air is of the same charge in every orientations, there is no temperature difference both air and surface of indoor objects, and the particles are well mixed neglecting the indoor sources of particles .Therefore, the mass balance equation of inhaled particulate matter in small office buildings and residential building is:

$$
\begin{aligned}
\frac{d\left(C_{I ; i, j} V\right)}{d t} & =p Q_{i n} C_{o ; i, j}+Q_{n} C_{O ; i, j} \\
& -C_{I ; i, j} \stackrel{\mathrm{a}}{k}_{d, k ; i, j} S_{k}-\left(Q_{i n}+Q_{n}\right) C_{I ; i, j}
\end{aligned}
$$

Where $i$ and $j$ are the chemical ingredient and the dynamical diameter of particles, respectively; $C_{o ; I, j}$ is outdoor inhaled particulate matter concentration; $C_{I ; i, j}$ is indoor inhaled particulate matter concentration; $t$ is times; $\mathrm{k}$ is an index referencing each of the three major surface orientations in the building(upward facing, downward facing, and vertical); $V_{d, k ; I, j}$ is the deposition velocity for orientation $k ; p$ is the particle penetration factor; $V$ is the volume of room; $S k$ is the surface area with orientation towards $k ; Q_{\text {in }}$ and $Q_{n}$ are the infiltration and natural ventilation airflow rates, respectively. Natural ventilation refers to airflow through open windows and doors, while infiltration refers to airflow through the remainder of the building shell. Equation(1) shows indoor inhaled particulate matter concentration depends on inhaled particulate matter penetration factor, the deposition velocity and outdoor inhaled particulate matter concentration.

\section{Penetration FACTOR MOdel}

The penetration factor of particle to the building defense is related to Brownian diffusion, gravitational settling, deposition and inertial impaction.

\section{A. Penetration Factor Caused by Gravity Sedimentation}

Assuming cracks with regular geometry, smooth inner surfaces and steady airflow, inhaled particulate matters concentration at the entrance equal to the entering airstream concentration ${ }^{[3]}$. So the penetration factor due to gravitational settling is

$$
p_{g}=1-\frac{V_{S} L}{H U}
$$

where Vs is the deposition velocity through cracks; $L$ and $H$ are the Length and height of cracks, respectively; $U$ is the average velocity of air through cracks.

Because of the airflow itinerant state is laminar in the cause of air penetrating indoor, the airflow velocity is 
decided by cracks height, length, and the pressure difference of both sides, but irrelevant to cracks structure. The following equation shows the relation of $Q$ and pressure difference $\Delta P$ :

$$
\Delta P=\frac{12 \mu L}{w H^{3}} Q+\frac{\rho_{a} C_{n}}{2 H^{2} w^{2}} Q^{2}
$$

Where $\mu$ is the air viscosity; $g$ is acceleration of gravity; $K_{m}$ is correction coefficient; $\rho_{p}$ is the particle density; $d_{p}$ is the particle diameter; $Q$ is the air flow which is related to the pressure diffreence both indoor and outdoor; $w$ is total length of cracks.

\section{B. Penetration Factor Caused by Diffusion}

The penetration factor due to particle diffusion through the way is shown by

$$
p_{d}=\exp \left(-\frac{1.967 D_{P M} L}{(H / 2)^{2} U}\right)
$$

where $D_{P M}$ is the diffusion coefficient of single fixed media. ${ }^{[4,5,6]}$

\section{Simulation of Penetration Factor}

Figure 1 is the variation of penetration factor in different height of cracks as a function of particle size. When $\mathrm{h}$ equals $1 \mathrm{~mm}$, the penetration efficiency of particles with diameter in the range of $0.3 \sim 1.3 \mu \mathrm{m}$ is maximum which is close to 1 . The more reduction height of crack, the less penetration factor reduce, the less range of particle size. When $\mathrm{h}$ equals $0.25 \mathrm{~mm}$, the maximum penetration factor is 0.84 , maximum particle size is the range of $0.5 \sim 1.5 \mu \mathrm{m}$. But when $\mathrm{h}$ equals $0.1 \mathrm{~mm}$, the maximum penetration factor is 0.02 , then particles can hardly penetrate the building defense. The main reason of the maximum Penetration factor in a certain diameter range of is that the bigger particles deposit the inner surface of building defense because of gravity easily, but the smaller particle deposit the inner surface of building defense because of Brownian motion, so the penetrating factor is smaller.

Figure 2 the variation of penetration factor in different length of cracks as a function of particle size. Figure 2 shows that the penetration factor decrease with increase of the length of cracks. When the particle size is $1 \sim 2.5 \mu \mathrm{m}$, $\mathrm{L}=3 \mathrm{~cm}$, penetration factor greater than $0.95, \mathrm{~L}=6 \mathrm{~cm}$, penetration factor greater than 0.97 , and $\mathrm{L}=9 \mathrm{~cm}$, penetration factor greater than 0.99 , close to 1 . When the diameter is less than $1 \mu \mathrm{m}$, the penetration factor in different length of cracks are all very small, almost zero. When the particle size is larger than $10 \mu \mathrm{m}$, the penetration factor varies largely with the length of cracks. The longer cracks, the smaller penetration factor. This explains that the large particles has not reached the export subsidence on the wall surface because of gravity. In addition, influence of height of cracks on the particle penetration factor is much greater than that of length of crack.

Figure 3, 4 and figure 5 are the variation of penetration factor with the different pressure difference when cracks

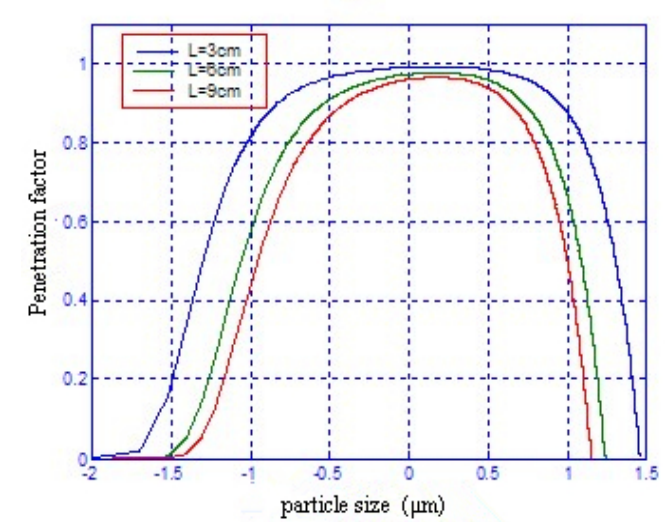

Figure 1. the variation of penetration factor in different height of cracks

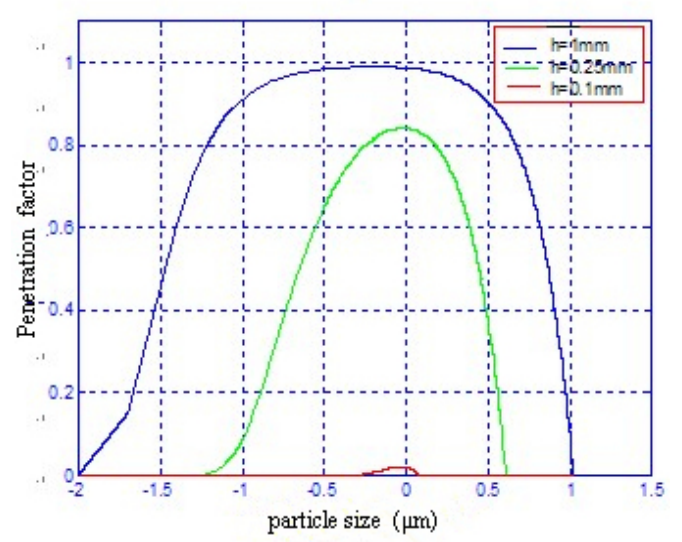

Figure 2. the variation of penetration factor in different length of cracks

height is $1 \mathrm{~mm}, 0.25 \mathrm{~mm}$ and $0.1 \mathrm{~mm}$ respectively. When equals $0.25 \mathrm{~mm}$, the variation of penetration factor with the different pressure difference in height of $0.25 \mathrm{~mm}$ is more obvious than that of height of $1 \mathrm{~mm}$, the less pressure difference, the more penetration factor. With $\mathrm{h}$ is $0.25 \mathrm{~mm}$ and $\Delta \mathrm{P}$ is $4 \mathrm{~Pa}$, the penetration factor of particles in diameter of $6 \sim 10 \mu \mathrm{m}$ is more than 0.4 , the maximum penetration factor appears in the diameter of $9 \mu \mathrm{m}$, reaching about 0.44 . With $\Delta \mathrm{P}$ is $7 \mathrm{~Pa}$, the penetration factor of particles in diameter of $5 \sim 14 \mu \mathrm{m}$ is more than 0.5 , the maximum penetration factor appears in the diameter of $9 \mu \mathrm{m}$, reaching about 0.57 . With pressure difference of $10 \mathrm{~Pa}$, the penetration factor of particles in diameter of $6 \sim 13 \mu \mathrm{m}$ is more than 0.6, the maximum penetration factor appears in the diameter of $9 \mu \mathrm{m}$, reaching about 0.64 . With height of $0.1 \mathrm{~mm}$, when pressure difference is $4 \mathrm{~Pa}$, the penetration factor of particles in all range of diameter is close to zero. When pressure difference is $7 \mathrm{~Pa}$, the maximum penetration factor is less than 0.04 . In result, the more longer crack, the more penetration factor. The more bigger pressure different, the more penetration factor. When $h$ is less than $0.1 \mathrm{~mm}$, and $\Delta \mathrm{P}$ is less than $4 \mathrm{~Pa}$, particles can't penetrate the gap, where the penetration factor is 0 . The simulation results is agreement with the experimental study of reference. 


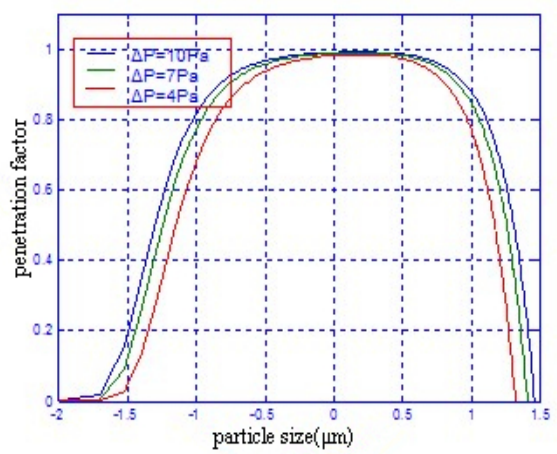

Figure 3. $\mathrm{h}=1 \mathrm{~mm}$ effect of pressure difference on penetration factor

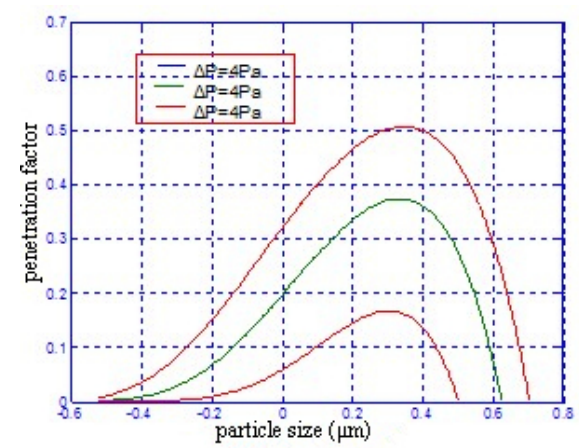

Figure 4. $\mathrm{h}=0.25 \mathrm{~mm}$ effect of pressure difference on

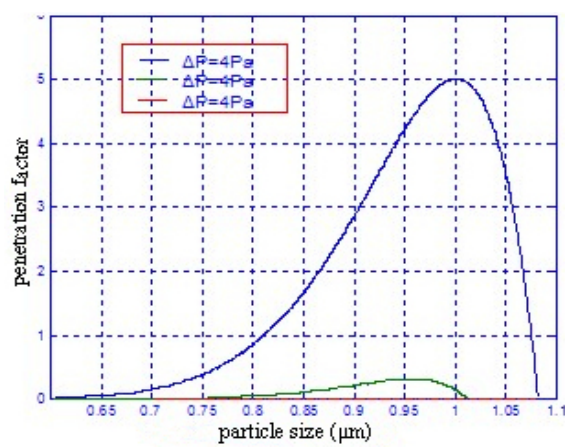

Figure 5. $\mathrm{h}=0.1 \mathrm{~mm}$ effect of pressure difference on penetration factor

\section{Simulation OF Deposition Ratio MODEL}

Deposition is one of the modes to reduce indoor particle concentration which results from Brownian diffusion, gravitational settling turbulence diffusion and inertial impaction. Brownian diffusion and turbulence diffusion decide the deposition velocity of particles smaller than $0.1 \mu \mathrm{m}$, while gravitational settling and inertial impaction decide that of particles larger than $0.1 \mu \mathrm{m} .{ }^{[7]}$

Because of the low velocity airflow, indoor particle can all deposit without rebound and re-suspending. supposing particles flow keep constant within the whole boundary layer, then

$$
J=-\left(e_{p}+D_{M P}\right) \frac{\llbracket C}{\llbracket y}
$$

$e_{p}$ is particle turbulence diffusion coefficient; $y$ is the distance of particle to object surface; $C$ is particle concentration.

Considering the impact of gravity, turbulent diffusion and Brownian diffusion on inhaled particulate matters settling with the deposition velocity given, the particle flow equation on the level smooth surface in the vicinity of the boundary layer is ${ }^{[9,10]}$

$$
J=-\left(e_{p}+D_{M D}\right) \frac{\mathbb{q} C}{\mathbb{q} y} \pm{ }_{V_{S}} C
$$

The particle deposition velocity on the downward surface is $v_{d d}=v_{d v}-v_{s}$, while the particle deposition velocity on the upward surface is $v_{d d}=v_{d v}+v_{s}$. Supposed $A_{S}, A_{d}$ and $A_{u}$ are total deposition areas of vertical, upward and downward surface, respectively, the total deposition ratio is

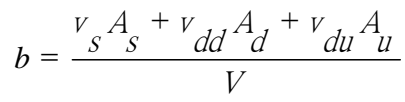

Figure 6 is deposition velocity of particulate matter in vertical smooth surface, which depends mainly on the friction velocity, and the friction velocity related to the room air flow rate and the size of the room. Deposition velocity of particles larger than $1 \mu \mathrm{m}$ in a vertical surface remains constant, but very little. The deposition mechanism of particles of size less than $1 \mu \mathrm{m}$ is mainly brown diffusion and turbulent dispersion. Figure 7 is deposition velocity of particulate matter in the upward horizontal surface. The deposition velocity of large particles in the upward horizontal surface has not varied in friction velocity. This also implies that the Brown diffusion and turbulent diffusion doesn't affect the main mechanism of the deposition velocity of larger diameter particles. In addition, the deposition velocity of particles in $0.01 \sim 0.1 \mu \mathrm{m}$ reaches a minimum, so gravity deposition of particles larger than $1 \mu \mathrm{m}$ is more obvious. When the particle size is greater than $1 \mu \mathrm{m}$, the effect of friction velocity on particle deposition velocity is very small.

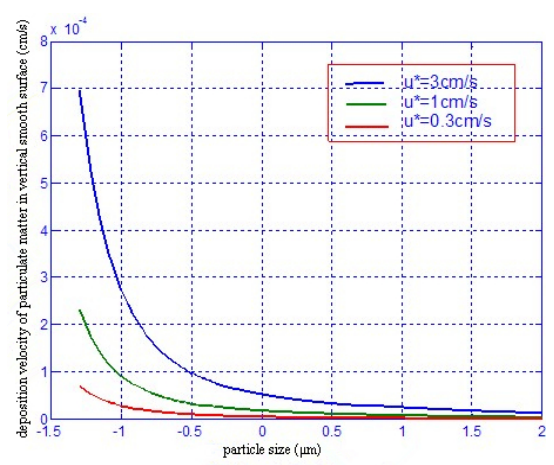

Figure 6. deposition velocity of particulate matter in vertical smooth surface

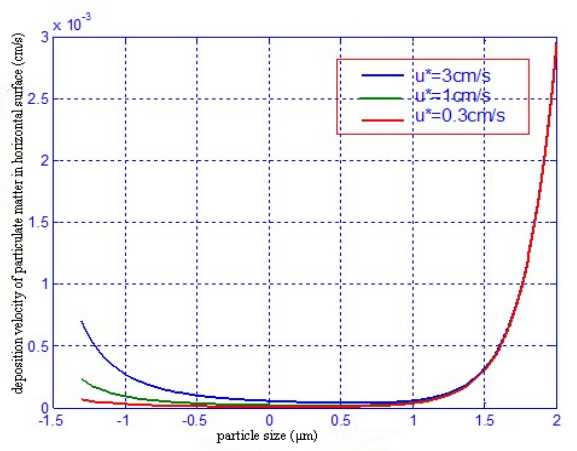

Figure 7. deposition velocity of particulate matter in horizontal surface 

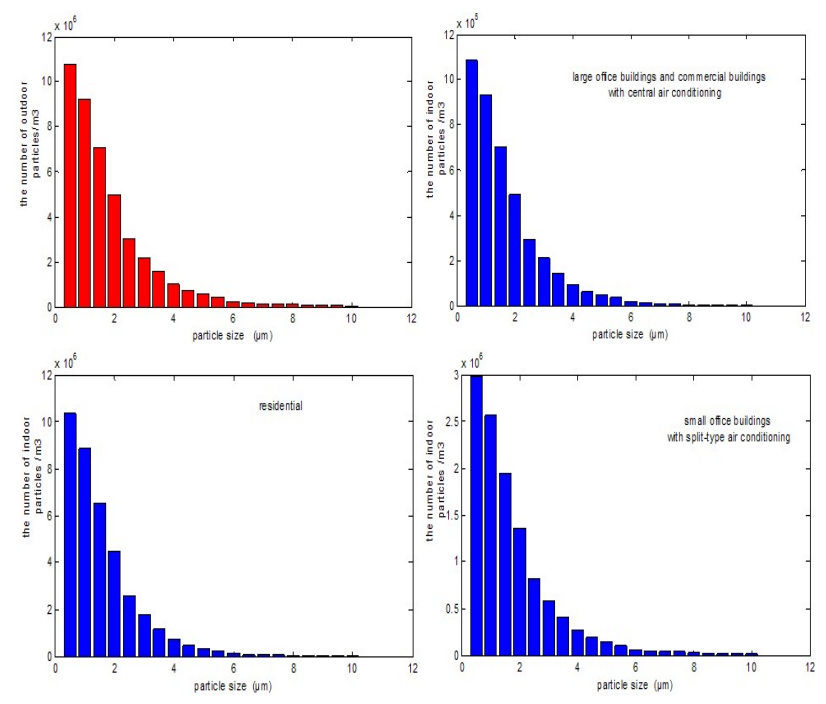

Figure 8. simulation results of number concentration

\section{Prediction of CONCENTRATION AND PARTICLE SizE DisTRIBUTION OF INDOOR INHALABLE PARTICULATE MATTERS}

The room simulated is $3 \mathrm{~m}$ height, $4 \mathrm{~m}$ width and $5 \mathrm{~m}$ length, which has a door in size of $0.9 \mathrm{~m}$ height and $2.1 \mathrm{~m}$ length, a single-layer aluminum alloy casement window with sealing strip in size of $1.5 \mathrm{~m}$ height and $1.2 \mathrm{~m}$ width. Assuming no furniture and decoration indoor, smooth inner surfaces, pressure difference between indoor and outdoor is $10 \mathrm{~Pa}$, building defense structure cracks is linear, $h=1 \mathrm{~mm}, L=3 \mathrm{~cm}$. Avoiding standard difference of the data selected to cause errors, the ventilation number of all types of building is from references.

Figure 8 shows the simulation results of number concentration of indoor particles of large office buildings and commercial buildings with central air conditioning, small office buildings with split-type air-conditioning and residential, respectively. For large office buildings and commercial buildings with central air conditioning, three simulated concentrations of indoor particle are significantly lower than that of outdoor particles with the same diameter and the efficiency of filter on eliminating particles is very obvious. The higher filtering efficiency is the smaller influence on concentration of outdoor particles of indoor particles. This also means, filter and deposition can effectively prevent the particles into indoor. As a result of filtering effect of building cracks on particle, the amplitude of reduction is not big, most of the particles are through the cracks into the room. Compared with the simulations of large office buildings and commercial buildings equipped with central air condition, in the room with split air conditioning outdoor particulate matter into indoor is in a much larger scale.

\section{CONCLUSION}

According to the real-time changes, the concentration and size distribution of indoor suspended particulate matters are predicted and analysed. The dissertation analysis the factors to effect the concentration and size distribution, established the mass balance model adopting the deposition velocity, penetration factor, as well as air flow indoor as input its parameters. Combining experimental measurement data and building envelope characteristics with the concentrations outdoor particles and other related data, the concentrations and particle size distribution of indoor suspended particulate matter is predicted by simulation.

However, due to the limitation of the experimental conditions, the research results also need further verification. According to the actual construction conditions, we need improve the particle deposition research the building structure cracks size and air permeability, real-time detect the concentration and size distribution of indoor and outdoor, so verify the founded models by experimental method.

\section{REFERENCES}

[1] Thatcher T. L, Lai A. C. K, Rosa Moreno-Jackson, et al. Effects of room furnishings and air speed on particle deposition rates indoors. Atmospheric Environment. 2002, 36(11): 1811 1819

[2] Enkins P.L, Phillips T.J, Mulberg E.J, et al. Activity patterns of Californians: Use of and Proximity to Indoor Pollutant Sources. Atmospheric Environment, 1992, 26(12): $2141 \sim 2148$ http://dx.doi.org/10.1016/0960-1686(92)90402-7

[3] Lee, K.W., and Gieseke, J.A. Simplified calculation of aerosol penetration through channels and tubes. Atmospheric Environment, 1980, 14(7): 1089-1094 http://dx.doi.org/10.1016/00046981(80)90039-6

[4] Thomas C.W.Tung, Christopher YH. Chao, John Burnett. A methodology to investigate the particulate penetration coefficient through building shell. Atmospheric Environment. 1999, 33(6): 881-893 http://dx.doi.org/10.1016/S1352-2310(98)00299-4

[5] De-Ling Liu, William W. Nazaroff. Modeling pollutant penetration across building envelopes. Atmospheric Environment, 2001,35(26) : $4451 \sim 4462$ http://dx.doi.org/10.1016/S13522310(01)00218-7

[6] Liu D.L, Nazaroff W.W. Particle penetration through windows. In: Proc Indoor Air's California, U.S.A 2002,1(1):862 867

[7] Hanley.J.T., Ensor, D.S., Smith, D.D. et al. Fractional aerosol filtration efficiency of induct ventilation air cleaners. Indoor Air, 1994, 4(2): 169 178

[8] Baker, P.H., Sharpies, S., Ward, LC. Air-flow through cracks. Building and Environment, 1987, 22(3): $293 \sim 304$ http://dx.doi.org/10.1016/0360-1323(87)90022-9

[9] Holmberg Sture, Li Yuguo. Modelling of the indoor environmentparticle dispersion and deposition. Indoor Air, 1998, 8(2):113 $122 \mathrm{http}: / / \mathrm{dx}$. doi.org/10.1111/j.1600-0668.1998.t01-2-00006.x

[10] Thatcher T. L, Lunden M. M., Revzan K. L, et al. A concentration rebound method for measuring particle penetration and deposition in the indoor environment. Aerosol Science and Technology, 2003, 37(8):847 864 http://dx.doi.org/10.1080/02786820300940

\section{AUTHORS}

Hongli Liu is a associate professor and master supervisor with School of Automation, Wuhan University of Technology, Wuhan, CO 430074 China(email:james97@163.com).

Xiong Zhou is student with School of Automation, Wuhan University of Technology, Wuhan, CO 430074, China (e-mail:zhouxion_422@126.com).

Huan Sun is student with School of Automation, Wuhan University of Technology, Wuhan, CO 430074, China(e-mail:sunhuan920@163.com).

This article is an extended and modified version of a paper presented at the International Conference on Mechanical Engineering, Automation and Material Science (MEAMS2012), held 22-23 December 2012, Wuhan, China. Received 14 February 2013. Published as resubmitted by the authors 25 March 2013. 